\title{
Adolescent health and wellbeing: advocating a role for urban design
}

In The Lancet Commission on adolescent health and wellbeing ${ }^{1}$, George C Patton and colleagues give a comprehensive overview of the unprecedented global health challenges facing young people aged between 10 and 24 years. These health challenges demand more action and investment to protect the future of our young people and our society. The authors emphasise intersectoral and multicomponent actions 


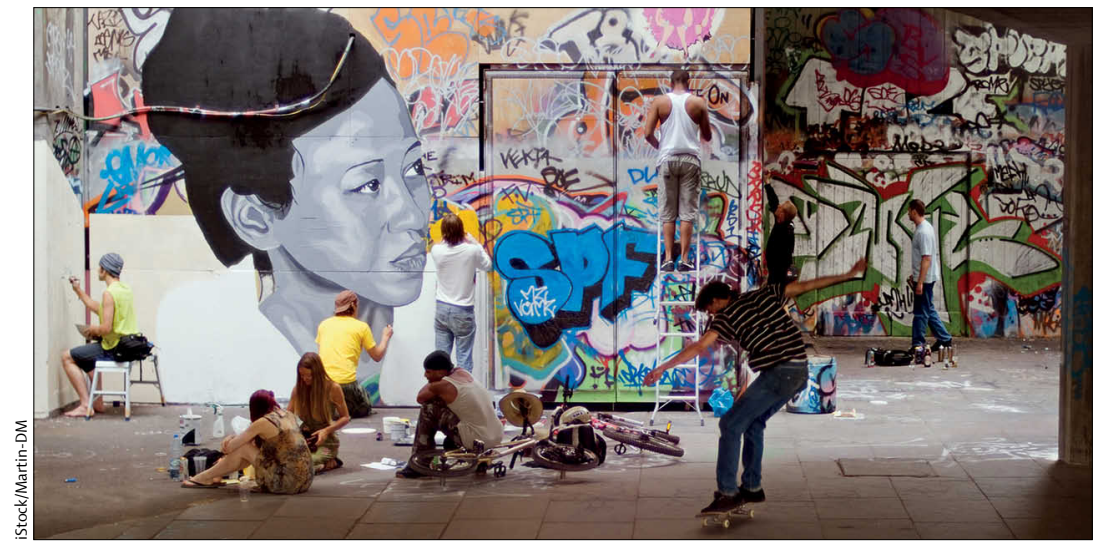

combining "structural, media, community, online, and school-based elements." ${ }^{11}$ But missing from the current debate is a role for urban design. We advocate that more attention be paid to urbanism that supports adolescent health and wellbeing. Although a role for a new urbanism in supporting public health outcomes

For The Lancet Series on urban design, transport, and health see https://www.thelancet.com/ series/urban-design is gaining traction, including in The Lancet Series on urban design, transport, and health, this discussion has inadequate focus on adolescents. With one in five young people (aged 6-19 years) in the USA now obese, ${ }^{2}$ and projections predicting that obesity rates in the USA will rise to more than $45 \%$ by $2030,{ }^{3}$ it is time to act and maximise the potential of urban design to improve adolescent health and wellbeing.

The concept of an active city, for example, supports health-promoting transport systems and safe communities, and enables more walking, cycling, and public transport use. This concept is particularly pertinent to adolescent health. Urban design elements that are associated with overall improvements to levels of physical activity and health outcomes in adolescents (including lower obesity risk) include residential density, mixed land use, street connectivity, walkability of the neighbourhood and school environs, street aesthetics, availability of safe crossings, and nearby green spaces. ${ }^{4,5}$ A systematic review $^{6}$ of interventions designed to promote active living in adolescents found that the most effective interventions were road safety measures (eg, reducing traffic speed or traffic calming) and providing safe routes to school (eg, accessible pavements). Adolescent health is also affected by the opportunities that their local neighbourhood and surroundings offer. Easy access to recreational facilities (eg, football pitches and basketball courts) and neighbourhood parks make it easier for adolescents to be active and to socialise with their peers. But children in deprived areas are nine times less likely to have access to green spaces and places to play than children in more affluent areas, ${ }^{7}$ and $32 \%$ of $16-24$-year-olds in a UK survey reported that they never visited a local park. ${ }^{8}$ Well designed urban communities offer a variety of places for young people to meet friends, talk, play formally and informally, become engaged in the community, roam freely, explore, and be active. Investing in urban design to also support adolescent mental health should be a stronger priority, given the growing need for youth mental health-care provision. ${ }^{9}$

In an article published in $2017,^{10}$ we set out an urban health model and conceptual framework for researching and steering efforts to support adolescent health and wellbeing through good urban design. The resulting model is based on Brian Little's socioecological model of wellbeing, ${ }^{11}$ called personal project analysis. This framework explores youth wellbeing from the context of a young person's needs, lifestyles, and aspirations through the lens of personal goals and integrates the social and physical context in which adolescents manage their goals. This approach has been applied to identify restorative urban niches that support emotional wellbeing in adolescents. ${ }^{12}$ We believe that exploring the interaction between age-specific adolescent goals and urban landscape affordances-including physical, social, digital, and emotional affordances-offers a new approach to better understand how we can design our cities for adolescent health

We argue that more adolescent-responsive urban design processes should be open to explore new technologies to forge mobility in, and engagement with, the city. The concept of a playable city, for example, affords opportunities for adolescents to interact with the city through smartphones, thereby promoting physical activity, social interactions, and meeting adolescent needs for adventure and excitement through gaming in a real-world context. Early studies ${ }^{13}$ indicate that gaming can help to increase moderate and vigorous physical activity by up to $20 \%$ as part of an active travel-to-school programme and can spur learning about what places are good for health, using smartphone technologies 
that provide health data feedback (eg, on physical activity levels and heart rate) in relation to the built environment while gaming. ${ }^{14}$

Furthermore, we advocate a role for the so-called green city in supporting adolescent health and emotional wellbeing. As well as promoting physical activity, the local outdoors provide restorative niches that support psychological wellbeing, with adolescents capitalising on any available nature space to help support mood regulation (eg, by building private dens and tree-houses), including local parks and urban fringe woodland. ${ }^{12}$ The new trend towards greening vacant land in deprived US cities, such as Detroit and Cleveland, offers long-term strategies for investing in neighbourhood renewal and can also sustain health and wellbeing. Young people can be at the core of these urban regeneration processes by re-appropriating underused open green spaces. Examples showing how urban designers and young people cocreate alternative usages include temporary cinemas under a flyover or an outdoor gallery space, as part of joint efforts to draw attention to active recreation in urban green infrastructure. It is important to welcome young people's activities in the heart of the city, ie, socialising in lively open spaces connected to cultural spaces or residential areas, by moderating conflicting interests and regulations (eg, for noise). It is from an increased sense of belonging and ownership that a more active use of open green spaces can develop.

Although there appears to be an overall agreement about the importance of social determinants to adolescent health, we advocate that urban design warrants far more attention than it has received, including an important role for public open space, neighbourhood park access, and urban electronic games. Understanding health and wellbeing from the perspective of what matters to adolescents-combined with cocreation in urban design processes-is crucial to these new approaches.

\section{*Jennifer Roe, Martin Knöll}

Center for Design and Health, School of Architecture, University of Virginia, Charlottesville, VA 22903, USA (JR); and Department of Architecture, Technische Universität Darmstadt, Darmstadt,

Germany (MK)

jjr4b@virginia.edu

We declare no competing interests.

1 Patton GC, Sawyer SM, Santelli JS, et al. Our future: a Lancet commission on adolescent health and wellbeing. Lancet 2017; 387: 2423-78.

2 Hales CM, Carroll MD, Fryar CD, Ogden CL. Prevalence of obesity among adults and youth: United States, 2015-2016. NCHS Data Brief 2017; 288: 1-8.

3 Organisation for Economic Cooperation and Development. Obesity Update 2017. 2017. http://www.oecd.org/health/health-systems/ObesityUpdate-2017.pdf (accessed July 30, 2018).

4 Ding D, Sallis JF, Kerr J, et al. Neighborhood environment and physical activity among youth a review. AmJ Prev Med 2011; 41: 442-55.

5 Carlson JA, Saelens BE, Kerr J, et al. Association between neighbourhood walkability and GPS-measured walking, bicycling and vehicle time in adolescents. Health Place 2015; 32: 1-7.

6 Audrey S, Batista-Ferrer H. Healthy urban environments for children and young people: a systematic review of intervention studies. Health Place 2015; 36: 97-117.

7 National Children's Bureau. Greater Expectations: raising aspirations for our children. 2013. https://www.ncb.org.uk/sites/default/files/uploads/ documents/Policy_docs/GEXP_final\%20WEB.pdf (accessed July 30, 2018).

8 YouGov. Parks, Green Spaces and Young People. 2017. https://www. groundwork.org.uk/Handlers/Getlmage.ashx?IDMF=42fa4ed6-d20c-4f788db8-0bda91b3d03a\&w=704\&h=880 (accessed July 30, 2018)

9 Roe J, Roe A. Urban design for adolescent mental health. In: Bhugra D, Ventriglio A, Castaldelli-Maia JM, eds. Urban Mental Health. Oxford: Oxford University Press (in press)

10 Knöll M, Roe J. Ten questions concerning a new adolescent health urbanism. Build Environ 2017; 126: 496-506.

11 Little BR. Well-doing: personal projects and quality of lives. Theory Res Educ 2014; 12: 329-34.

12 Roe JJ, Aspinall PA. Teenager's everyday 'doings' and the restorative niches that support them. Int J Environ Res Public Health 2012; 9: 3227-44

13 Coombes E, Jones A. Gamification of active travel to school: a pilot evaluation of the Beat the Street physical activity intervention. Health Place 2016; 39: 62-69.

14 Halblaub M, Knöll M. Stadtflucht-Learning about healthy places with a location-based game. Navigationen 2016; 16: 101-18.
For codesign efforts to activate urban green spaces see https://prehealth.eu/stimulate/ 